\title{
The arch bridge sign: a newly described CT feature of the coronavirus disease-19 (COVID-19) pneumonia
}

\author{
Ruodai Wu ${ }^{1 \#}$, Wei Guan ${ }^{2 \#}$, Zhenhua Gao ${ }^{3}$, Nashan $\mathrm{Wu}^{1}$, Yungang $\mathrm{Lv}^{1}$, Yumeng $\mathrm{Liu}^{1}$, Rui Mi ${ }^{1}$, \\ Junqing $\mathrm{Xu}^{1}$ \\ ${ }^{1}$ Department of Radiology, Shenzhen University General Hospital, Shenzhen University Clinical Medical Academy, Shenzhen, China; ${ }^{2}$ Department \\ of Nuclear Medicine, the First People's Hospital of Foshan, Foshan, China; ${ }^{3}$ Department of Radiology, Huiya Hospital, the First Affiliated Hospital, \\ Sun Yat-Sen University, Guangzhou, China \\ \#These authors contributed equally to this work.
}

Correspondence to: Junqing Xu. Department of Radiology, Shenzhen University General Hospital, Shenzhen University Clinical Medical Academy, Shenzhen 518055, China. Email: junqingxu@126.com.

\begin{abstract}
Background: To investigate the distribution of CT features and also to introduce a novel described CT feature of coronavirus disease-19 (COVID-19) pneumonia.

Methods: A series of radiologic signs in 11 COVID-19 patients were summarized and made morphometric analysis.

Results: A special sign termed as "the arch bridge sign" owing to its morphological mimicking an arch bridge was firstly introduced. Statistical analyze showed that the subpleural area is the priority distribution location (14/14) and the sign inclined to perform in those patients in a relatively early stage (6/8) and with moderate clinical severity (8/8). Segment VI in lower lobe involved most (6/14). In this retrospective study, other characteristic radiologic signs of COVID-19 pneumonia were analyzed synchronously. A series of radiologic signs were identified in bilateral lungs with a bias towards segment VI, I + II and X. Segment VI had the largest number of each sign. Ground-glass opacities (GGOs), subpleural distribution pattern and vessels dilatation were the top three most common signs among them.

Conclusions: The recognition of the arch bridge sign may benefit patient care by earlier definitive diagnosis of COVID-19 pneumonia. The lesions of COVID-19 pneumonia distributed mainly in the backlung segments, which characteristic may light new ideas in clinical treatment and nursing strategy.
\end{abstract}

Keywords: Coronavirus infections; tomography; X-ray computed; pneumonia; viral; lung diseases

Submitted May 25, 2020. Accepted for publication Jun 25, 2020.

doi: 10.21037/qims-20-688

View this article at: http://dx.doi.org/10.21037/qims-20-688

\section{Introduction}

The Director-General of WHO characterized the coronavirus disease-19 (COVID-19) situation as a pandemic associated with substantial morbidity and mortality based on "alarming levels of spread and severity, and by the alarming levels of inaction” on March 11, 2020 (1). There are more than 3.6 million confirmed case of COVID-19 with 247,503 fatalities in the world (2). The confirmed diagnosis of
COVID-19 mainly depends on viral nucleic acid detection in respiratory secretions or blood based on real time fluorescent RT-PCR technology (3). Unfortunately, maybe due to insufficient viral material for detection or improper extraction of nucleic acid from specimen, quite a number of patients with COVID-19 showed as false negative in initial detection, even for more than twice (4-6). Recent researches suggest PCR testing of nasopharyngeal swabs is not a sensitive test for COVID-19 at early stages of the clinical 
presentation. Chest CT may be helpful even seems to play an important role in some situations such as early detection of severe or critical cases or demonstrates remarkable pulmonary lesions in some COVID-19 pneumonia patients with false negative result in initial nucleic acid detecting (4). Also, more sensitive test kit for virus or antibody need to be further investigated.

During image review of the patients in our institutions, we recognized a special pattern on thin sliced chest CT and named it the arch bridge sign for the arched contour outlines the domain of ground-glass opacity (GGO) or consolidation, mimics like an arcade aperture in a GGO bridge. This specific imaging has not been previously described in radiology literature. The recognition of this radiological sign may benefit patient care by earlier definitive diagnosis of COVID-19 pneumonia.

\section{Methods}

Our institutional review board waived written informed consent for this retrospective case series that evaluated deidentified data and involved no potential risk to patients.

\section{Population and CT image data acquisition}

Eleven patients with COVID-19 pneumonia confirmed were enrolled. The cases series was drawn from the entire population of clinically symptomatic, COVID19 -positive in our hospitals. Referral procedures to COVID-19 designated hospital would start once the patients were confirmed the diagnosis of SARS-CoV-2 infection. Chest CT (Revolution CT scanner, GE Healthcare) examination follows the common chest plain scanning protocol in supine position with the slice thickness $1.25 \mathrm{~mm}$.

\section{CT review and interpretation}

All the chest radiographs were reviewed by two radiologists (both with 12 years of experience in chest imaging) independently and consensus finally.

The CT images were evaluated with both lung and mediastinal windows. The main analysis indicator are the number of involved segments, presence of a series of radiologic signs including subpleural distribution pattern, GGOs, patchy consolidation, fibrous stripes, air bronchogram, crazy paving sign, coin-like nodules, vessels dilatation pattern, a tree-in-bud appearance, and pleural effusion based on the Fleischer Society glossary of terms for thoracic imaging (7).

Here we first described a special sign (arch bridge sign) in COVID-19 pneumonia patients. We measured the central height passing through the central lobular arteries of spared lung tissue as the diameter of "bridge hole".

\section{Statistical analysis}

Statistical analyses were performed using SPSS version 25.0 (IBM Corp., Armonk, NY, USA).

\section{Results}

\section{Demographics}

CT images of 11 patients confirmed positive for SARS$\mathrm{CoV}-2$ virus were collected. $\mathrm{M} / \mathrm{F}$ ratio: $3 / 8$, age ranged from 19 to 65 years (The median age was 41.5 years). The timeline and spectrum of symptoms from initial onset to the CT examination day was shown in Figure 1. Six patients were in their early stage of time interval (within 2 days from initial disease onset) when CT examination were performed. Two and three patients were in their intermediate (3-5 days) and late ( $>5$ days) interval respectively.

\section{CT images analysis}

The number of involved lung segments was 64 . Ten patients (90.9\%) had multiple lesions except one whose isolated lesions in segment $\mathrm{X}$ located in left lower lobe. Six patients (54.5\%) had no less than 3 lobes involved, 4 patients (36.4\%) had only 1 lobe involved, and 1 patient $(9.1 \%)$ had 2 lobes involved. As to the involved segments, the top 3 were segment VI, I + II and X in sequence (Table 1).

The amount of segments with GGO, subpleural distribution pattern, vessels dilatation, patchy consolidation, crazy paving sign, air bronchogram, fibrous stripes and coin-like nodule were 57, 56, 50, 30, 25, 22, 17 and 16 respectively. The top 3 radiologic signs were GGOs, subpleural distribution pattern and vessels dilatation pattern, with the same bias to segment VI, I + II and X in sequence. The frequency of each radiologic sign in different segments was shown in Table 2. Figure 2 showed a case with multiple signs from above.

\section{Characteristics of arch bridge sign in chest $C T$}

In addition, a sign locating in subpleural area was noticed. It 


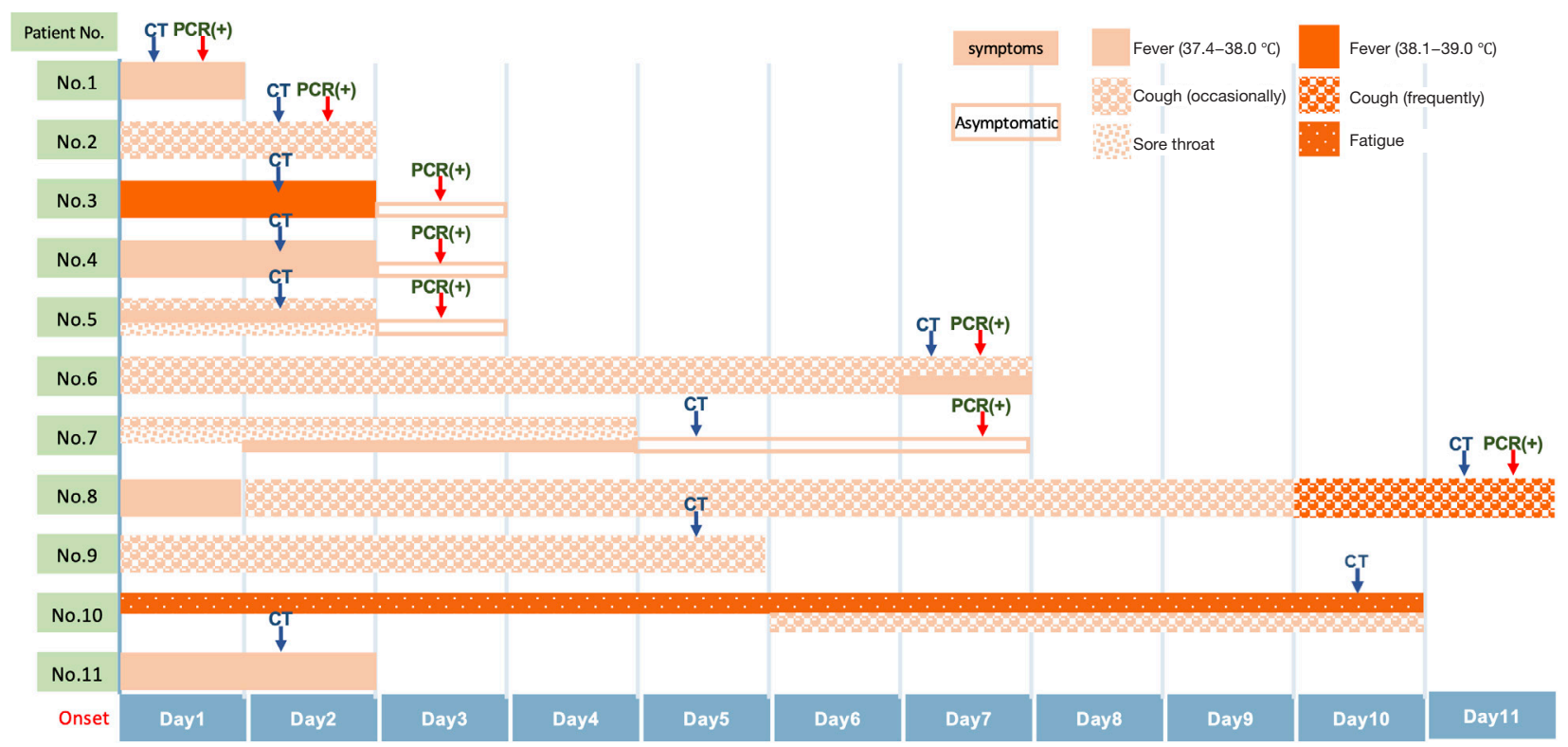

Figure 1 Timeline and spectrum of symptoms from initial onset to the CT examination day.

Table 1 The number of lesions in the segments involved

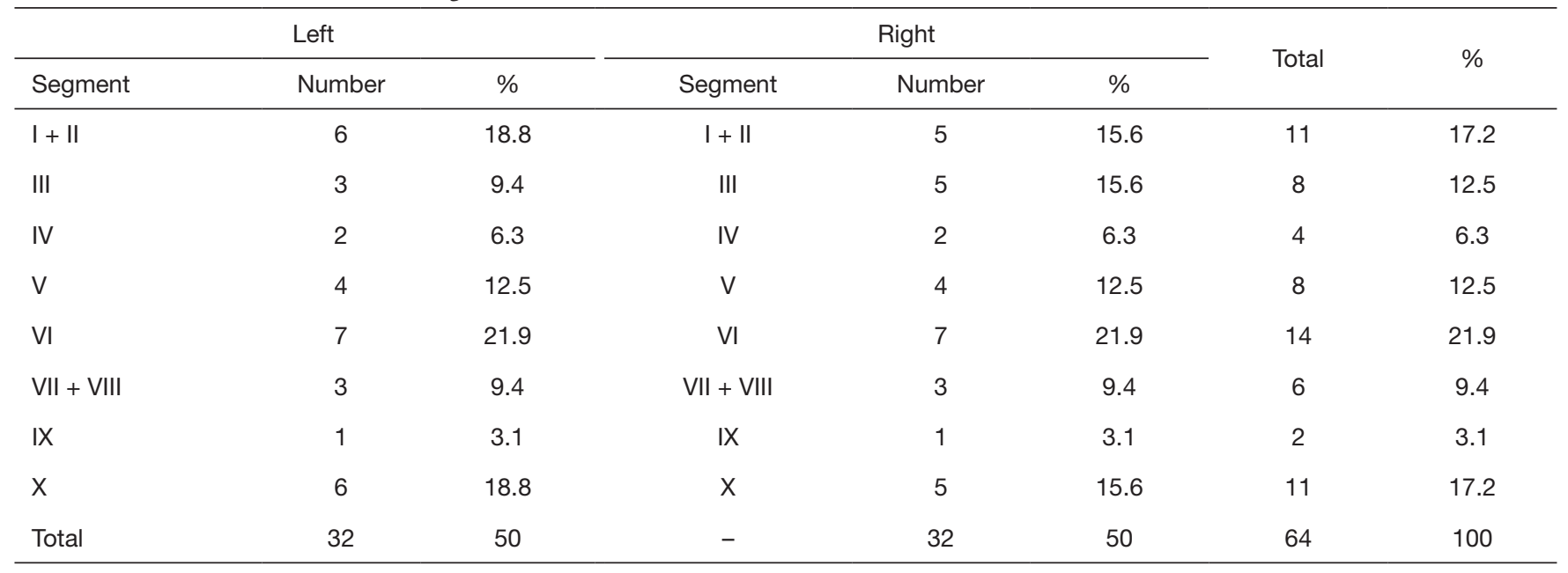

appeared as GGO or mixed GGO and consolidation, with a smooth concave margin towards the pleural side, and this arched margin outlines the contour of the relatively spared lung tissue between lesion and pleural. We termed it as "the arch bridge sign" owing to the arched contour mimics an arcade aperture in a lesion bridge (Figure 3). The arcade hole-like spared lung tissue of this sign ranged in diameter from 10.0 to $15.2(13.1 \pm 1.8) \mathrm{mm}$. The number of segments with this sign was 14 (Table 2). We also observed double arches bridge formed sometime (Figure 4) and occasionally two arches were connected together. Occasionally the arch could towards other direction rather than towards the pleural (Figure 5).

The characteristics of patients with arch bridge sign were displayed in Figure 6. CT imaging of eight patients showed the sign. Six out of eight patient was in their early stage and all patients manifested moderate clinical severity according to the criteria of 6th version guideline of Chinese General Office of National Health Committee (3). All lesions with arch bridge sign were subpleural distribution and half patients showed localized consolidation in GGO. 
Table 2 The frequency of radiologic sign in pulmonary segments (\%)

\begin{tabular}{lccccccccc}
\hline Segment & GGO & SUBP & ANGE & CONS & CPS & ABG & FIBR & COIN & ArBS \\
\hline I + II & $14.0(8 / 57)$ & $17.9(10 / 56)$ & $16.0(8 / 50)$ & $20.0(6 / 30)$ & $8.0(2 / 25)$ & $4.5(1 / 22)$ & $17.6(3 / 17)$ & $6.3(1 / 16)$ & $14.3(2 / 14)$ \\
III & $14.0(8 / 57)$ & $10.7(6 / 56)$ & $10.0(5 / 50)$ & $13.3(4 / 30)$ & $12.0(3 / 25)$ & $13.6(3 / 22)$ & $11.8(2 / 17)$ & $25.0(4 / 16)$ & $7.1(1 / 14)$ \\
IV & $3.5(2 / 57)$ & $5.4(3 / 56)$ & $8.0(4 / 50)$ & $6.7(2 / 30)$ & $8.0(2 / 25)$ & $4.5(1 / 22)$ & $5.9(1 / 17)$ & $6.3(1 / 16)$ & $0(0 / 14)$ \\
V & $12.2(7 / 57)$ & $12.5(7 / 56)$ & $6.0(3 / 50)$ & $16.7(5 / 30)$ & $8.0(2 / 25)$ & $9.1(2 / 22)$ & $17.6(3 / 17)$ & $25.0(4 / 16)$ & $0(0 / 14)$ \\
VI & $24.6(14 / 57)$ & $23.2(13 / 56)$ & $26.0(13 / 50)$ & $20.0(6 / 30)$ & $20.0(5 / 25)$ & $31.8(7 / 22)$ & $11.8(2 / 17)$ & $25.0(4 / 16)$ & $42.9(6 / 14)$ \\
VII + VIII & $8.8(5 / 57)$ & $7.1(4 / 56)$ & $10.0(5 / 50)$ & $3.3(1 / 30)$ & $12.0(3 / 25)$ & $13.6(3 / 22)$ & $17.6(3 / 17)$ & $6.3(1 / 16)$ & $14.3(2 / 14)$ \\
IX & $3.5(2 / 57)$ & $3.6(2 / 56)$ & $4.0(2 / 50)$ & $3.3(1 / 30)$ & $8.0(2 / 25)$ & $0(0 / 22)$ & $0(0 / 17)$ & $0(0 / 16)$ & $0(0 / 14)$ \\
X & $19.3(11 / 57)$ & $19.6(11 / 56)$ & $20.0(10 / 50)$ & $16.7(5 / 30)$ & $24.0(6 / 25)$ & $22.7(5 / 22)$ & $17.6(3 / 17)$ & $6.3(1 / 16)$ & $21.4(3 / 14)$ \\
\hline
\end{tabular}

GGO, ground-glass opacity; SUBP, subpleural distribution pattern; ANGE, angioectasis; CONS, consolidation; CPS, crazy paving sign; $A B G$, air bronchogram; FIBR, fibrous stripes; COIN, coin-like nodule; ArBS, arch bridge sign.
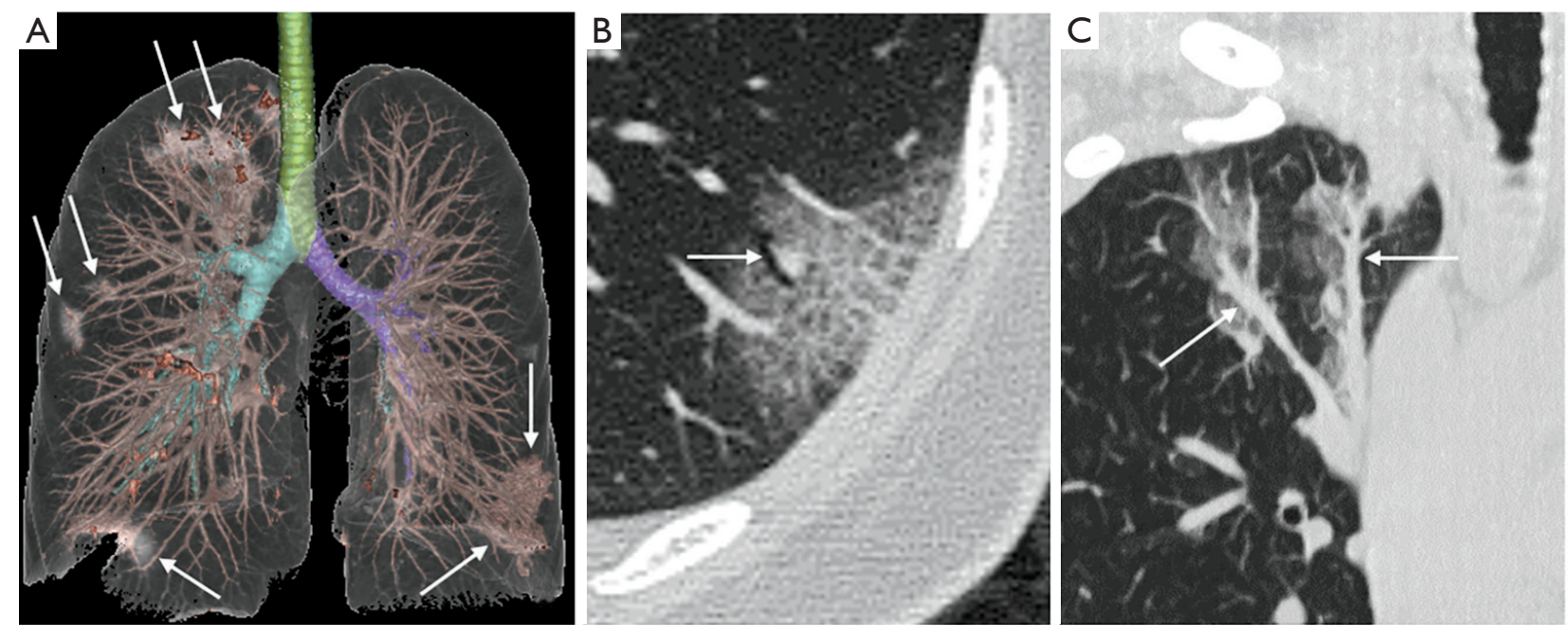

Figure 2 A 35-year old female presenting with initial 1 day's fever. The VR image (A) gave a visual representation of multiple subpleural lesions (arrows) in bilateral lungs; the axial magnified image of one of these lesions (B) depicted typical "crazy paving sign" and air bronchogram (arrow), and the coronal MPR image of another lesion (C) depicted vessels dilatation inside the GGOs (arrow). MPR, multiplanar reformation; GGO, ground-glass opacity.

\section{Discussion}

Lung is the most common affected organ by SARS-CoV-2. In our study, the lesions could locate in different lobes or segments of bilateral lungs but more commonly in lower lobes (Table 1), and the VI, I + II and X segments turned out to be the most common involved sites. By contrary, the segment IX was spared mostly (Table 2). This pattern of distribution may be caused by how SARS-CoV-2 spread, gravity or respiratory movement. Other features observed in our research (Figure 2) to a great extent highlight other research's descriptions for COVID-19 pneumonia (8-10). Interestingly, we noticed that there were 14 subpleural GGOs or consolidation (most were GGOs) in eight patients, showing a sharp margin which is concave towards the pleural side, and this arch-like margin outlines the contour of the relatively spared lung tissue between the lesion and pleural. This sign mimics an arch bridge with an internal lucent hole. To our best knowledge, there was no any published study describing this chest radiologic sign in COVID-19 pneumonia or other kinds of lung diseases, we termed it as "the arch bridge sign". Of the lesions 

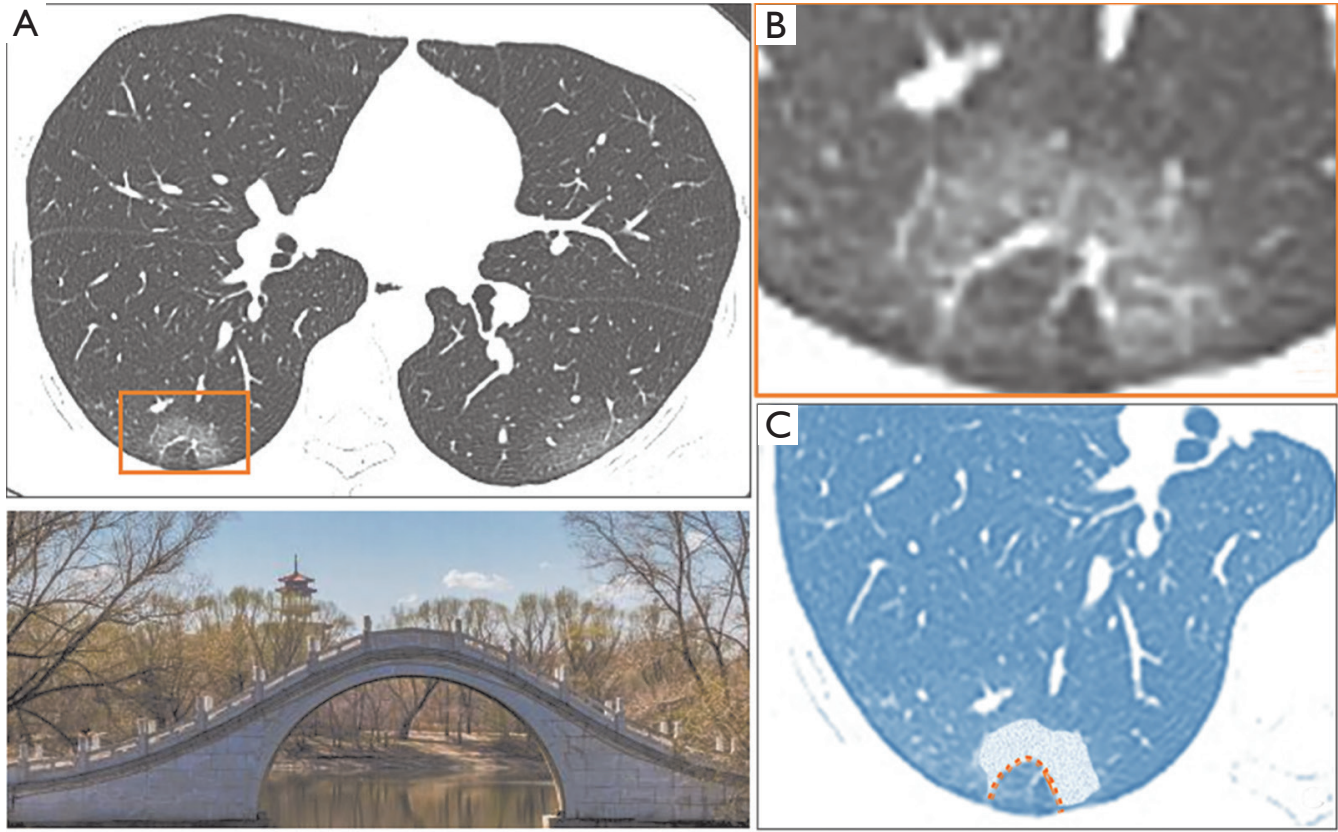

Figure 3 A 37-year-old female presenting with fever and cough who had a definitely epidemiological exposure. The plain axial thin slice HRCT (A) demonstrates a subpleural GGOs in segment VI of right lower lobe, the magnified (B) and sketched (C) images of the lesion show the subpleural GGO, with a sharp arch-like margin (dotted line in C), encompassing a semicircular spared lung tissue. This pattern mimics a single arch bridge. Left lower quadrant shows a traditional single arch bridge. HRCT, high-resolution CT; GGO, ground-glass opacity.

with the arch bridge sign in our study, the diameter of the "bridge hole" ranging from 10.0 to $15.2(13.1 \pm 1.8) \mathrm{mm}$, and spot or tree-bud-like centrilobular component also could be identified in some lesions, these features indicated that the "bridge hole" is a single secondary lobule (Figure $6)$. Studies had shown that the SARS-CoV-2 targeting receptors ACE2 express in alveolar cells, endothelial cells and arterial smooth muscle cells of lung (11-13). Our observation show that the arch bridge sign formed because of the infiltrating of lesion is blocked by interlobular septum of the secondary pulmonary lobule. It suggested that secondary pulmonary lobules may be the basic unit of virus invasion. It also interpolates the reason the sign was more often to be seen in subpleural area as the pulmonary interstitium in this area is richer than the other part of lungs. In our study, the notable absence of the specific arch bridge sign were distributed subpleural, and clinical severity assessment for all patients were moderate (Figure 5). So, we infer that the sign maybe indicate the nature of relatively early and localized lesion and indicate a relatively mild clinical situation.

Several studies have shown that the COVID-19 pneumonia usually appears as multifocal pulmonary GGOs or/and consolidation which may be similar to those of severe acute respiratory syndrome (SARS) and Middle East respiratory syndrome (MERS) (14-16). Among them, the lesions could locate in different lobes or segments of bilateral lungs but more commonly in lower lobes (14-16) which were consistent with our study. But still our research suggest that COVID-19 pneumonia has its special imaging feature. We found the distribution of lesions dominantly in the back-lung segments. Giving heed to the distribution pattern may provide new ideas in clinical treatment and nursing strategy, such as prone positioning clinical nursing. Experimental studies provide convincing evidence that prone positioning influences the generation and evolution of ventilator induced lung injury (VILI) which arises from repeated application of high mechanical forces that either tear fragile tissue directly or initiate signaling that culminates in inflammatory change by altering gas exchange in the lung (17-19). The distribution of the lesion was first counted by single lesion among the imaging researches about COVID-19 pneumonia which may reflect the feature better.

Our study had several limitations. We had a small size 

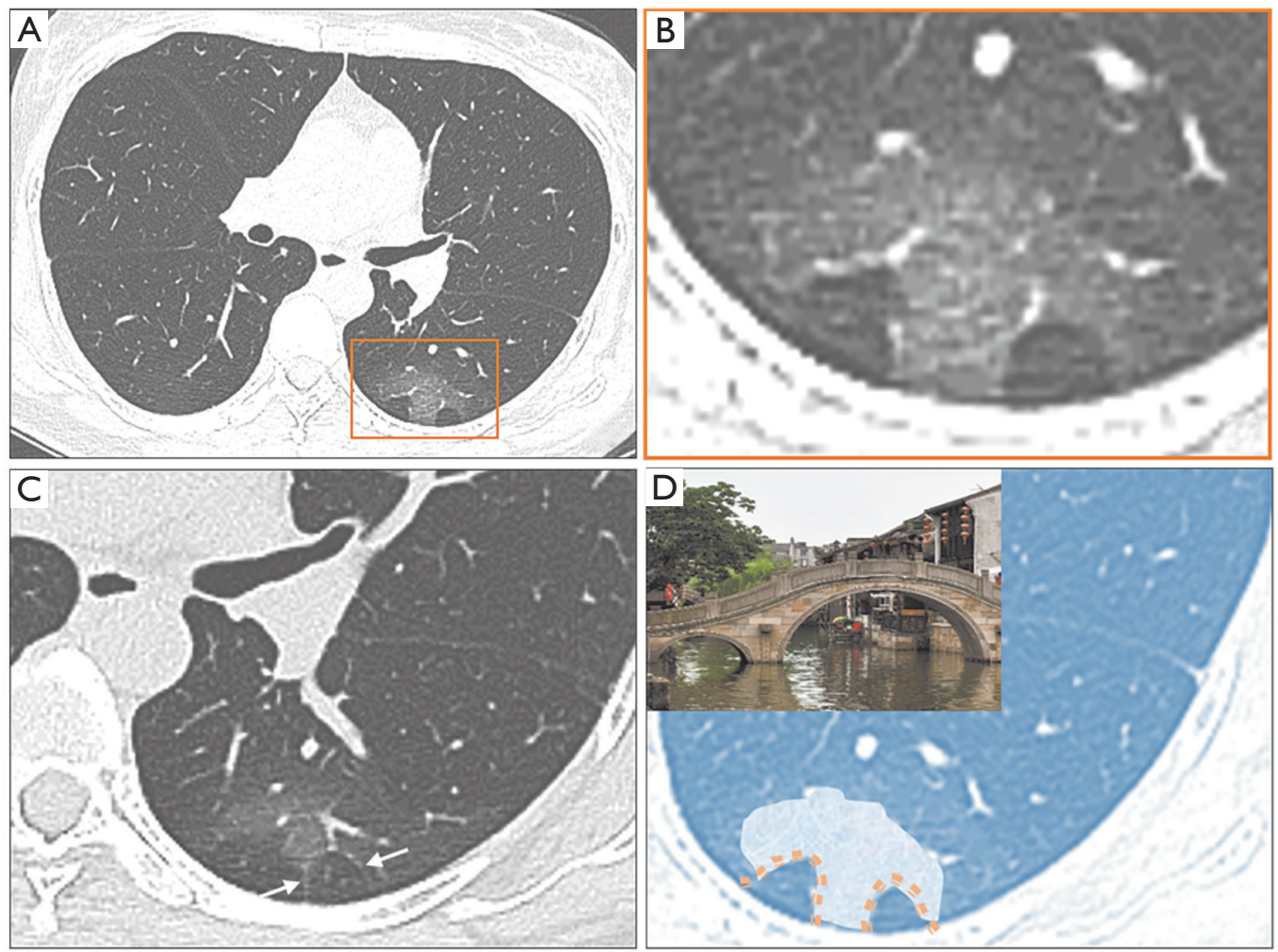

Figure 4 A 37-year-old female, presenting with fever and cough. The axial non contrast thin slice HRCT (A) and focal magnified image (B) demonstrate a subpleural GGOs in segment VI in left lower lobe. A normal interstitial septum was showed in the lower part of the same lesion (C) which indicates the lucency inside lesion is a single normal secondary lobule. The sketched image (D) shows the sharp arch-like margin (dotted line), and these features made this lesion looks like a double arches bridge. HRCT, high-resolution CT; GGO, ground-glass opacity.
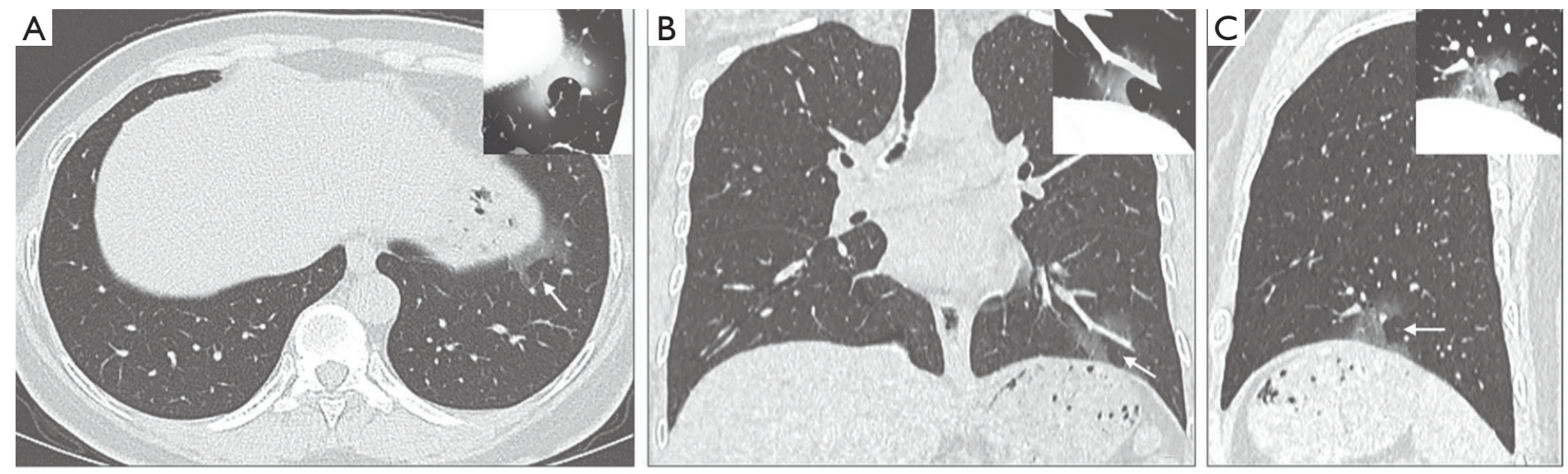

Figure 5 A 45-year-old female presenting with fever. The plain axial thin slice HRCT (A), coronal (B) and sagittal (C) MPR images demonstrate a subpleural GGO located in left lower lobe. A tree-bud-like hyper density (white arrow) could be seen inside the lucent area which was encompassed by the "C" form GGO, it is a typical centrilobular artery. This tip further indicates the lucency inside lesion is a single normal secondary lobule. HRCT, high-resolution CT; MPR, multiplanar reformation; GGO, ground-glass opacity. 


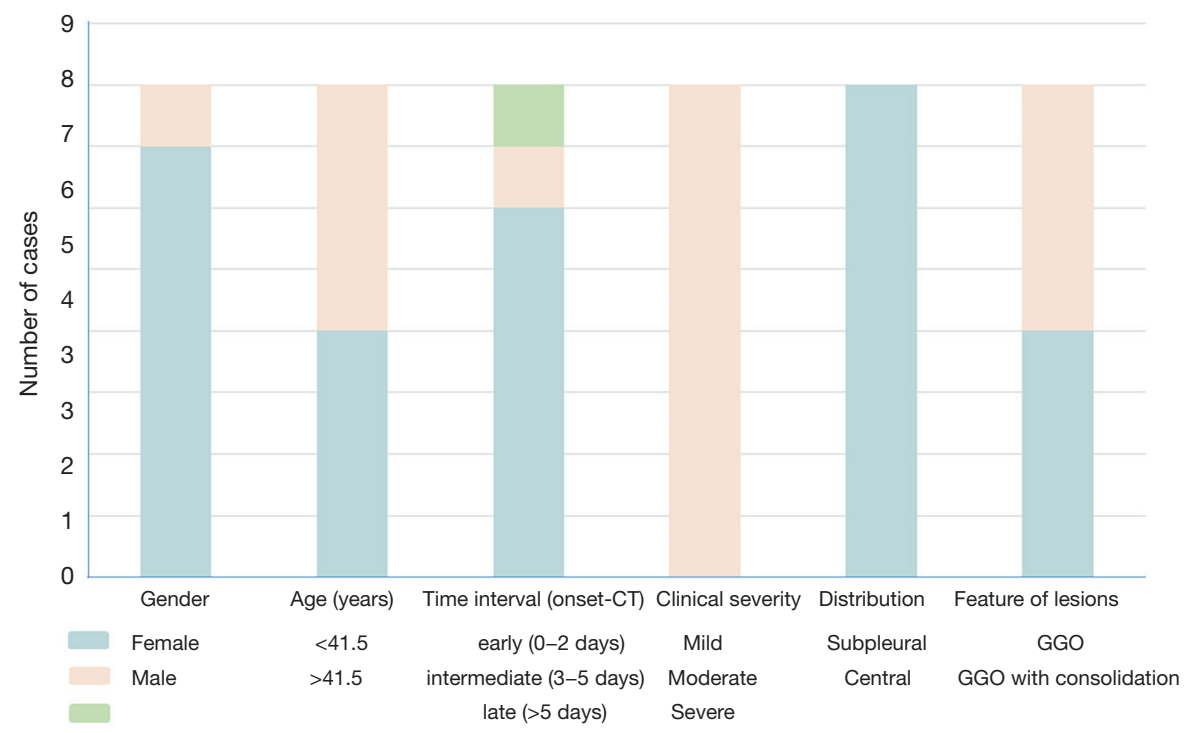

Figure 6 Characteristics of patients with arch bridge sign. GGO, ground-glass opacity.

sample that the conclusion needs to be confirmed with larger size sample researches. We analyzed the features without control groups so that we could not investigate the value of these signs in differential diagnosis. Additionally, we limited our study in the lack of follow-up CT data to understand the outcome of each sign.

In conclusion, our retrospective study indicated the COVID-19 pneumonia has certain characteristics in chest radiology, giving heed to the distribution characteristics of dominantly in the back-lung segments, new ideas in clinical treatment and nursing strategy may be lighted, such as prone positioning clinical nursing. Moreover, it is the first time to term and suggest the "arch bridge sign" which may reflect the early histopathologic feature of COVID-19 pneumonia. We shared this original finding and hope other scholars can pay attention to the sign and conduct further research about its diagnostic performance or prognostic association.

\section{Acknowledgments}

Funding: The work is supported by "Natural Science Foundation of Shenzhen University General Hospital" (SUGH2019QD011).

\section{Footnote}

Conflicts of Interest: All authors have completed the ICMJE uniform disclosure form (available at http://dx.doi. org/10.21037/qims-20-688). The authors have no conflicts of interest to declare.

Ethical Statement: Institutional Review Board approval was obtained. The research has been approved by Shenzhen University Ethical approval. Written informed consent was waived by the Institutional Review Board because we just used the routine CT image.

Open Access Statement: This is an Open Access article distributed in accordance with the Creative Commons Attribution-NonCommercial-NoDerivs 4.0 International License (CC BY-NC-ND 4.0), which permits the noncommercial replication and distribution of the article with the strict proviso that no changes or edits are made and the original work is properly cited (including links to both the formal publication through the relevant DOI and the license). See: https://creativecommons.org/licenses/by-nc-nd/4.0/.

\section{References}

1. WHO Director-General's opening remarks at the media briefing on COVID-19 - 11 March 2020. 2020. Available online: https://www.who.int/dg/speeches/detail/whodirector-general-s-opening-remarks-at-the-mediabriefing-on-covid-19---11-march-2020 (Accessed 22nd April, 2020).

2. World Health Organization. Coronavirus disease 2019 
(COVID-19): Situation Report - 107. Available online: https://www.who.int/docs/default-source/coronaviruse/ situation-reports/20200506covid-19-sitrep-107. pdf?sfvrsn=159c3dc_2 (Accessed 6 May, 2020).

3. China General Office of National Health Committee. Notice on the issuance of a program for the diagnosis and treatment of novel coronavirus (2019-nCoV) infected pneumonia (trial sixth edition). 2020. Available online: http://www.nhc.gov.cn/yzygj/s7653p/202002/8334a8326d d94d329df351d7da8aefc2.shtml

4. Xu J, Wu R, Huang H, Zheng W, Ren X, Wu N, Ji B, Lv Y, Liu Y, Mi R. Computed tomographic imaging of 3 patients with coronavirus disease 2019 pneumonia with negative virus real-time reverse-transcription polymerase chain reaction test. Clin Infect Dis 2020. [Epub ahead of print]. doi: 10.1093/cid/ciaa207.

5. Xie X, Zhong Z, Zhao W, Zheng C, Wang F, Liu J. Chest CT for typical 2019-nCoV pneumonia: relationship to negative RT-PCR testing. Radiology 2020. [Epub ahead of print]. doi:10.1148/radiol.2020200343.

6. Zou X, Chen K, Zou J, Han P, Hao J, Han Z. Singlecell RNA-seq data analysis on the receptor ACE2 expression reveals the potential risk of different human organs vulnerable to $2019-\mathrm{nCoV}$ infection. Front Med 2020;14:185-92.

7. Hansell DM, Bankier AA, MacMahon H, McLoud TC, Müller NL, Remy J. Fleischner Society: glossary of terms for thoracic imaging. Radiology 2008;246:697-722.

8. Chung M, Bernheim A, Mei X, Zhang N, Huang M, Zeng X, Cui J, Xu W, Yang Y, Fayad ZA, Jacobi A, Li K, Li S, Shan H. CT imaging features of 2019 novel coronavirus (2019-nCoV). Radiology 2020;295:202-7.

9. Gattinoni L, Taccone P, Carlesso E, Marini JJ. Prone position in acute respiratory distress syndrome. Rationale, indications, and limits. Am J Respir Crit Care Med 2013;188:1286-93.

10. Gattinoni L, Vagginelli F, Carlesso E, Taccone P, Conte V, Chiumello D, Valenza F, Caironi P, Pesenti A. Prone-Supine Study Group. Decrease in $\mathrm{PaCO} 2$ with prone position is predictive of improved outcome

Cite this article as: Wu R, Guan W, Gao Z, Wu N, Lv Y, Liu Y, Mi R, Xu J. The arch bridge sign: a newly described CT feature of the coronavirus disease-19 (COVID-19) pneumonia. Quant Imaging Med Surg 2020;10(7):1551-1558. doi: 10.21037/qims20-688 in acute respiratory distress syndrome. Crit Care Med 2003;31:2727-33.

11. Galiatsou E, Kostanti E, Svarna E, Kitsakos A, Koulouras V , Efremidis SC, Nakos G. Prone position augments recruitment and prevents alveolar overinflation in acute lung injury. Am J Respir Crit Care Med 2006;174:187-97.

12. Bernheim A, Mei X, Huang M, Yang Y, Fayad ZA, Zhang N, Diao K, Lin B, Zhu X, Li K, Li S, Shan H, Jacobi A, Chung M. Chest CT findings in coronavirus disease-19 (COVID-19): relationship to duration of infection. Radiology 2020;295:200463.

13. Shi H, Han X, Jiang N, Cao Y, Alwalid O, Gu J, Fan Y, Zheng C. Radiological findings from 81 patients with COVID-19 pneumonia in Wuhan, China: a descriptive study. Lancet Infect Dis 2020;20:425-34.

14. Pan Y, Guan H, Zhou S, Wang Y, Li Q, Zhu T, Hu Q, Xia L. Initial CT findings and temporal changes in patients with the novelcoronavirus pneumonia (2019-nCoV): a study of 63 patients in Wuhan, China. Eur Radiol 2020;30:3306-9.

15. Chen Y, Guo Y, Pan YH, Zhao ZJ. Structure analysis of the receptor binding of 2019-nCoV. Biochem Biophys Res Commun 2020;525:135-40.

16. Hamming I, Timens W, Bulthuis ML, Lely AT, Navis G, Van Goor H. Tissue distribution of ACE2 protein, the functional receptor for SARS coronavirus. A first step in understanding SARS pathogenesis. J Pathol 2004;203:631-7.

17. Kanne JP. Chest CT finding in 2019 novel coronavirus (2019-nCoV) infections from Wuhan, China: Key points for the radiologist. Radiology 2020;295:16-7.

18. Wong KT, Antoni GE, Hui DS, Lee N, Yuen EHY, Wu A, Leung CB, Rainer TH, Cameron P, Chung SSC, Sung JJY, Ahuja AT. Severe acute respiratory syndrome: radiographic appearances and pattern of progerssion in 138 patients. Radiology 2003;228:401-6.

19. Das KM, Lee EY, Langer RD, Larsson SG. Middle east respiratory syndrome coronavirus: What does a radiologist need to know? AJR Am J Roentgenol 2016;206:1193-201. 